\title{
IMPACT OF POLYCYCLIC AROMATIC HYDROCARBONS ON MALE REPRODUCTIVE HEALTH IN COAL TAR WORKERS
}

\author{
By \\ Mansour NA ${ }^{1}$, Anis $\mathrm{MT}^{2}$, Soror $\mathrm{KM}^{1}$ and Mohamed RS ${ }^{1}$ \\ ${ }^{1}$ Department of Occupational and Environmental Medicine, ${ }^{2}$ Department of Andrology, \\ Sexual Medicine and Sexual Transmitted Diseases, Faculty of Medicine, Cairo Univer- \\ sity.
}

Corresponding author: Mohamed RS: rateba.said@kasralainy.edu.eg

\begin{abstract}
Introduction: It's well known that exposure to polycyclic aromatic hydrocarbons (PAHs) increases the risk of cancer; however less is known about their adverse effects on male reproductive health. Aim of work: To assess the effects of occupational exposure to PAHs on male reproductive health in a company for coke production. Materials and methods: A cross sectional comparative study was performed on an exposed group of coal tar workers $(\mathrm{No}=45)$ and a matched control group $(\mathrm{No}=45)$. Personal interview with specially designed questionnaire and standardized self-completed questionnaire was done to assess the erectile dysfunction. Urinary 1-hydroxypyrene (1-OH Pyrene) and serum malondialdehyde (MDA) in addition to reproductive hormones and semen analysis were assessed. Results: The study revealed a statistically significant increase in the level of 1-OHpyrene, MDA and estradiol ratio among the exposed group with Mean \pm SD 8.42 $\pm 3.61,11.95 \pm 7.29$, $7.89 \pm 3.45$ vs $3.14 \pm 3.51,2.44 \pm 1.61,6.59 \pm 2.21$ respectively among the controls with $p<0.05$. As for reproductive hormones, no statistical significant differences were found between both groups. Erectile dysfunction score showed significant prevalence of moderate $(28.9 \%)$ and severe $(26.7 \%)$ grades of erectile dysfunction among the exposed group vs $11.1 \%$ and $8.9 \%$ respectively among the control $(\mathrm{p}<0.05)$. By doing Liner regression analysis, it was found that Testosterone and Estradiol ratio were the predictors for erectile dysfunction score $(\beta=0.96$ and 0.86 respectively) $(\mathrm{p}<0.05)$.

Concerning semen analysis, there was a statistically significant decrease in the seminal fluid volume, semen concentration and sperm motility (grade B) with increase of pus cells among exposed group compared to the control group $(\mathrm{p}<0.05)$ while no significant difference for other semen parameter. A significant positive correlation was found between 1-OHpyrene and MDA ( $\mathrm{r}=0.63$, $\mathrm{p}<0.001$ ), while no significant correlation was found between 1-OHpyrene, MDA on one side and
\end{abstract}


reproductive hormones on the other side $(\mathrm{p}>0.05)$. Conclusion and recommendations: The adverse health effect on the male reproductive system in the current study might be one of the hazards that can be attributed to occupational exposure to PAHs in coal tar workers. Regular wearing of good quality personal protective equipment, especially masks and gloves is highly recommended to decrease exposure to $\mathrm{PAH}$ in addition to screening with urinary 1-OH pyrene and serum MDA levels.

Keywords: Polycyclic aromatic hydrocarbons (PAHs), Malondialdehyde (MDA), 1-Hydroxypyrene (1-OHpyrene), Semen analysis and Reproductive health.

\section{Introduction}

Polycyclic aromatic hydrocarbons (PAHs) are lipophilic nonpolar chemical compounds characterized by the presence of two or more benzene rings (Ravindra et al., 2008). They are mainly derived from the incomplete combustion of organic materials and are usually found in the atmosphere as a mixture of different compounds. 1-Hydroxypyrene (1-OHpyrene), one of PAHs metabolites; is often used as a marker of exposure to them (Straif et al., 2005). Occupational exposure to PAHs may occur through inhalation of exhaust fumes as in mechanics, street vendors, or motor vehicle drivers. Exposure can also occurs in mining, metal working, or oil refining. Coal tar is among the byproducts of coke production and one of man-made sources of PAHs (Armstrong et al., 2004). Although the major routes of occupational exposure to PAHs is through inhalation, cutaneous absorption is of a growing awareness (Lerda, 2010).
Spermatogenesis is a complex cellular event that takes place in the seminiferous tubules epithelium and requires the involvement of a complex of peptides and hormones ( Sofikitis et al., 2008 and Sokol,2009). PAHs have been described to impair the reproductive system (Perera et al., 2005). Exposure to PAHs causes endocrine disruption activity and contributes to decreased testosterone and increased luteinizing hormone (LH) concentrations. These disruptions impair epididymal function and cause alteration in gametogenesis with further sperm morphological abnormalities (Jeng et al., 2013). Moreover, exposure to 1-OHpyrene (PAHs metabolites) impairs testicular endocrine and exocrine functions with alteration in epididymal microenvironment causing reduction in stored sperm density and sperm motility (Ramesh et al., 2008). 


\section{Aim of work}

To assess the effects of occupational exposure to PAHs on male reproductive health in a company for coke production.

\section{Materials and methods}

Study design: It is a cross sectional comparative study

Place and duration of the study: The study was performed in a company for Coke production during the period from December 2015 to August 2016. The company is comprised of three production plants: Coke plant, Tar plant and Nitrate plant.

Study sample: the study population consisted of an exposed group of coal tar plant workers (total number of workers was 55). Only 50 persons accepted to participate in the study after explanation of the objective and impact of the study with data confidentiality. Five from the 50 exposed workers were excluded after application of the exclusion criteria (two had hydrocele, two were on corticosteroid therapy for chronic lung diseases and one had pituitary adenoma). The exposed workers were further subdivided according to their job (Hsu et al., 2006) into the top side workers $(\mathrm{No}=20)$, the coke oven side workers $(\mathrm{No}=15)$ and the office side workers $(\mathrm{No}=10)$. A control group of 45 male subjects was selected matching the exposed group for age, sex, socioeconomic status and special habits of medical importance with no history of occupational exposure to PAHs or any diseases affecting hypothalamic pituitary testicular axis.

\section{Study methods:}

Each participant in the study was subjected to:

1. A specially designed detailed questionnaire including personal, occupational, reproductive, present, past and family histories.

2. Another standardized self-completed questionnaire from the international index of erectile dysfunction (IIEF-5) was used with a total score of 1-7: Severe erectile dysfunction(ED), 8-11: Moderate ED, 12-16:Mild-moderate ED,1721: Mild ED, 22-25: No ED (Rosen et al., 1999)

\section{General and local clinical exami- nation was carried out.}

\section{Laboratory investigations:}

A- Blood samples were collected by venipuncture into tubes containing ethylenediaminetetraacetic acid (EDTA). Plasma samples were separated by centrifugation at $3000 \mathrm{r} / \mathrm{min}$ for $10 \mathrm{~min}$ and stored at $-20 \mathrm{C}^{\mathrm{O}}$ until they were analyzed. 


\section{- Hormonal assessment:}

Follicle stimulating hormone (FSH), luteinizing hormone (LH), Estradiol (E2), Prolactin (PRL), Testosterone (T), Thyroid stimulating hormone (TSH) concentrations were measured by radioimmunoassay (RIA) provided by Beijing North Institute of Biological Technology, China and by thiobarbituric acid (TBA) (Daichi Pure Chemical Co. Ltd.Tokoyo)

- Assessment of Malondialdehyde

\section{level:}

This was done using the technique elicited by Han et al., 2010 and Ghanwat et al., 2016).

\section{B- Assessment of 1-hydroxypyrene} (1-OHpyrene) level in urine: The level of 1-hydroxyPyrene was determined using reverse-phase high performance liquid chromatography (HPLC) with wavelengths of 241 and $388 \mathrm{~nm}$ (Kang et al., 2007).

C-Semen analysis: Semen sample were obtained in a private room by masturbation into a sterile wide-mouth and metal-free glass container after a recommended 2-day sexual abstinence. After liquefaction at $37^{\circ} \mathrm{C}$ for $30 \mathrm{~min}$, conventional semen analysis was conducted in accordance with guidelines of WHO Laboratory Manual 2010 for the examination of human semen including semen volume, sperm concentration, sperm number per ejaculum and sperm motility using microcell slide and the computer-aided semen analysis (CASA system) (Hu et al., 2013) .

\section{Consent}

All subjects were informed about the purpose of the study and agreed to participate in the study. All personal information about the study participants was kept confidential.

\section{Ethical approval}

This study was approved by the internal Ethical Committee of Occupational and Environmental Medicine department, Faculty of Medicine, Cairo University. Approval from the factory manager was obtained.

\section{Data management}

Data were coded and entered using the statistical package SPSS version 15 (SPSS, Chicago, Illinois, USA). The mean values and standard deviation (Mean \pm SD) were estimated for quantitative variables and the frequency distribution for qualitative variables. Comparisons between exposed and control groups were done using Chi square $(\chi 2)$ test for qualitative variables and using the independent simple t-test as well as the analysis of variance (ANOVA test) followed by Post Hoc test for normally distributed quantitative variables. Correlations and regressions were done to test for the presence of linear relations between quantitative variables. $\mathrm{P}<0.05,0.01$ were considered statistically significant (Guller and DeLong, 2004). 


\section{Results}

Table (1): Demographic and laboratory data of the studied group.

\begin{tabular}{|l|c|c|c|}
\hline Parameters & $\begin{array}{c}\text { Exposed } \\
(\mathbf{N o = 4 5})\end{array}$ & $\begin{array}{c}\text { Control } \\
(\mathbf{N o = 4 5})\end{array}$ & p-value \\
\hline Age (years) $($ Mean \pm SD) & $5.35 \pm 33.80$ & $32.56 \pm 5.16$ & $>0.05$ \\
\hline Smoking $($ Yes/NO \%) & $60 / 40$ & $73.3 / 26.7$ & $>0.05$ \\
\hline-1 OHpyrene $(\mu \mathrm{mol} / \mathrm{mg}$ creatinine) & $3.61 \pm 8.42$ & $3.14 \pm 3.51$ & $<\mathbf{0 . 0 0 1 * *}$ \\
\hline MDA $(\mathrm{nmol} / \mathrm{ml})$ & $7.29 \pm 11.95$ & $2.44 \pm 1.61$ & $<\mathbf{0 . 0 0 1} * *$ \\
\hline FSH $(\mathrm{mIU} / \mathrm{ml})$ & $3.58 \pm 7.67$ & $6.96 \pm 3.24$ & $>0.05$ \\
\hline LH $(\mathrm{mIU} / \mathrm{ml})$ & $2.62 \pm 6.32$ & $5.87 \pm 2.22$ & $>0.05$ \\
\hline Prolactin $(\mathrm{ng} / \mathrm{ml})$ & $4.87 \pm 9.70$ & $11.23 \pm 5.1$ & $>0.05$ \\
\hline Estradiol $(\mathrm{pg} / \mathrm{ml})$ & $6.77 \pm 34.24$ & $31.40 \pm 7.22$ & $>0.05$ \\
\hline Testosterone $(\mathrm{ng} / \mathrm{ml})$ & $1.66 \pm 4.81$ & $5.08 \pm 1.39$ & $>0.05$ \\
\hline Estradiol ratio\# & $3.45 \pm 7.89$ & $6.59 \pm 2.21$ & $<\mathbf{0 . 0 5 *}$ \\
\hline TSH (uIU/ml) & $5.46 \pm 8.32$ & $4.27 \pm 4.34$ & $>0.05$ \\
\hline
\end{tabular}

\footnotetext{
* Data are presented as Mean $\pm \mathrm{SD} . \quad *$ :Estradiol ratio $=$ Estradiol $/$ Testosterone

FSH: Follicle stimulating hormone

LH: Luteinizing hormone

TSH: Thyroid stimulating hormone

MDA: Malondialdehyde

*: Statistically significant

**: Highly statistically significant
}

Table (1) showed significant increase of 1-OH Pyrene, Malondialdehyde and Estradiol ratio among exposed persons to polycyclic aromatic hydrocarbons when compared to the control group. 
Table (2): Erectile dysfunction (ED) score among the studied groups.

\begin{tabular}{|l|c|c|c|c|c|}
\hline & \multicolumn{2}{|c|}{ Exposed(No =45) } & \multicolumn{2}{|c|}{ Control(No =45) } & \multirow{2}{*}{} \\
\cline { 2 - 5 } Erectile dysfunction score & No. & \% & No. & \% & p-value \\
\hline No ED (22-25) & 7 & 15.6 & 13 & 28.9 & $>0.05$ \\
\hline Mild ED (17-21) & 8 & 17.8 & 15 & 33.3 & $>0.05$ \\
\hline Mild-Moderate ED (12-16) & 5 & 11.1 & 8 & 17.8 & $>0.05$ \\
\hline Moderate ED (8-11) & 13 & 28.9 & 5 & 11.1 & $<0.05^{*}$ \\
\hline Severe ED (1-7) & 12 & 26.7 & 4 & 8.9 & $<0.05^{*}$ \\
\hline
\end{tabular}

*: Statistically significant

Table (2) showed a statistically significant difference for moderate to severe erectile affection among exposed group compared to the control group $(\mathrm{p}<0.05)$.

Table (3): Mean \pm SD of semen parameters among the exposed and control groups.

\begin{tabular}{|c|c|c|c|c|c|c|}
\hline \multicolumn{2}{|c|}{ Semen parameters } & \multicolumn{2}{|c|}{$\operatorname{Exposed}\left(\mathrm{No}_{0}=45\right)$} & \multicolumn{2}{|c|}{ Control $(\mathrm{No}=45)$} & p-value \\
\hline \multicolumn{2}{|c|}{ Seminal Fluid Volume } & \multicolumn{2}{|c|}{$0.93 \pm 3.45$} & \multicolumn{2}{|c|}{$1.02 \pm 4.016$} & $<0.05 *$ \\
\hline \multicolumn{2}{|c|}{$\begin{array}{l}\text { Sperm concentration } \\
\text { (million) }\end{array}$} & \multicolumn{2}{|c|}{$190.11 \pm 112.35$} & \multicolumn{2}{|c|}{$269.5 \pm 131.07$} & $<0.05 *$ \\
\hline \multicolumn{2}{|c|}{ The overall motility } & \multicolumn{2}{|c|}{$25.06 \pm 0.70$} & \multicolumn{2}{|c|}{$24.64 \pm 3.84$} & $>0.05$ \\
\hline \multicolumn{2}{|c|}{ Motility Grade A (\%) } & \multicolumn{2}{|c|}{$18.56 \pm 9.21$} & \multicolumn{2}{|c|}{$21.33 \pm 10.79$} & $>0.05$ \\
\hline \multicolumn{2}{|c|}{ Motility Grade B (\%) } & \multicolumn{2}{|c|}{$47.89 \pm 12.36$} & \multicolumn{2}{|c|}{$42.11 \pm 13.42$} & $<0.05 *$ \\
\hline \multicolumn{2}{|c|}{ Motility Grade C (\%) } & \multicolumn{2}{|c|}{$16.11 \pm 7.75$} & \multicolumn{2}{|c|}{$17.11 \pm 9.26$} & $>0.05$ \\
\hline \multicolumn{2}{|c|}{ Motility Grade D (\%) } & \multicolumn{2}{|c|}{$17.67 \pm 15.54$} & \multicolumn{2}{|c|}{$18 \pm 14.9$} & $>0.05$ \\
\hline & & No & $\%$ & No & $\%$ & p-value \\
\hline \multirow{3}{*}{$\begin{array}{l}\text { Sperm } \\
\text { abnormal } \\
\text { form }\end{array}$} & Head defect & 32 & 71.1 & 31 & 68.9 & $>0.05$ \\
\hline & $\begin{array}{l}\text { Neck\& mid } \\
\text { piece defect }\end{array}$ & 10 & 22.2 & 11 & 24.4 & $>0.05$ \\
\hline & Tail defect & 18 & 40 & 12 & 26.7 & $>0.05$ \\
\hline \multicolumn{2}{|l|}{ Pus cells } & 30 & 66.7 & 10 & 22.2 & $<0.05 *$ \\
\hline
\end{tabular}

*: Statistically significant 
Table (3) showed statistically significant decrease in sperm concentration, motility Grade B (\%) and seminal fluid volume among exposed workers and increase in pus cells when compared to the control group

Table (4): ANOVA of the Mean \pm SD of 1-OHpyrene, MDA, sperm abnormal form, sperm motility and the measured hormones among different categories of the studied group.

\begin{tabular}{|c|c|c|c|c|c|c|}
\hline & $\begin{array}{c}\text { Topside } \\
\text { No=20 } \\
\text { Mean } \pm \text { SD }\end{array}$ & $\begin{array}{c}\text { Cokeside } \\
\text { No }=15 \\
\text { Mean } \pm \text { SD }\end{array}$ & $\begin{array}{c}\text { Officeside } \\
\text { No }=10 \\
\text { Mean } \pm \text { SD }\end{array}$ & $\begin{array}{c}\text { Control } \\
\text { No=45 } \\
\text { Mean } \pm \text { SD }\end{array}$ & ANOVA & p value \\
\hline $1 \mathrm{OH}$ pyrene $(\mu \mathrm{mol} / \mathrm{mg}$ creatinine $)$ & $2.41 \pm 11.68$ & $1.52 \pm 6.78$ & $4.34 \pm 1.11$ & $3.14 \pm 3.51$ & 43.08 & $<0.001 * *$ \\
\hline Serum MDA (nmol/ml) & $5.60 \pm 14.42$ & $8.98 \pm 11.63$ & $7.49 \pm 5.69$ & $2.44 \pm 1.61$ & 31.70 & $<0.001 * *$ \\
\hline Sperm abnormal form & $7.70 \pm 22.60$ & $6.21 \pm 20.60$ & $23.01 \pm 4.06$ & $17.13 \pm 7.27$ & 4.04 & $<0.05^{*}$ \\
\hline The overall motility & $26.87 \pm 4.06$ & $25.61 \pm 7.73$ & $25.60 \pm 6.21$ & $24.64 \pm 3.84$ & 0.72 & $>0.05$ \\
\hline FSH & $7.98 \pm 3.82$ & $7.06 \pm 3.61$ & $7.98 \pm 3.26$ & $6.96 \pm 3.24$ & 0.55 & $>0.05$ \\
\hline LH & $6.67 \pm 2.37$ & $6.21 \pm 3.07$ & $5.8 \pm 2.55$ & $5.87 \pm 2.22$ & 0.54 & $>0.05$ \\
\hline Prolactin & $7.48 \pm 2.77$ & $11.98 \pm 5.9$ & $10.74 \pm 4.99$ & $11.23 \pm 5.1$ & 3.43 & $<0.05^{*}$ \\
\hline Estradiol & $34.55 \pm 7.2$ & $33.84 \pm 7.57$ & $34.24 \pm 4.97$ & $31.40 \pm 7.22$ & 1.23 & $>0.05$ \\
\hline Testosterone & $4.57 \pm 1.19$ & $4.15 \pm 1.02$ & $6.28 \pm 2.39$ & $5.08 \pm 1.39$ & 4.97 & $<0.05^{*}$ \\
\hline Estradiol ratio & $8.06 \pm 2.89$ & $8.89 \pm 4.51$ & $6.03 \pm 1.85$ & $6.59 \pm 2.21$ & 3.66 & $<0.05^{*}$ \\
\hline TSH & $6.56 \pm 11.96$ & $4.61 \pm 4$ & $4.55 \pm 2.55$ & $4.27 \pm 4.34$ & 0.56 & $>0.05$ \\
\hline
\end{tabular}

FSH: Follicle stimulating hormone

LH: Luteinizing hormone

TSH:Thyroid stimulating hormone

MDA: Malondialdehyde

*: Statistically significant.

**: Highly statistically significant.

Table (4) showed statistically significant difference of 1-OH pyrene, MDA, sperm abnormal form, prolactin, testosterone and estradiol ratio among exposed subgroups when compared to the control group by ANNOVA test.

When doing Post Hoc test, the results showed statistically significant increase of $1-\mathrm{OH}$ pyrene among topside compared to cokeside and officeside subgroups ( $\mathrm{p}$ $<0.001$ ) and significant increase of serum malondialdehyde among topside group when compared to officeside group $(\mathrm{p}<0.05)$. As regard testosterone level, there was a statistically significant decrease in topside and cokeside groups compared to officeside group $(\mathrm{p}<0.005, \mathrm{p}<0.05)$ with significant decrease in estradiol ratio in officeside group when compared to topside and cokeside groups $(\mathrm{p}<0.5, \mathrm{p}<0.005)$. 


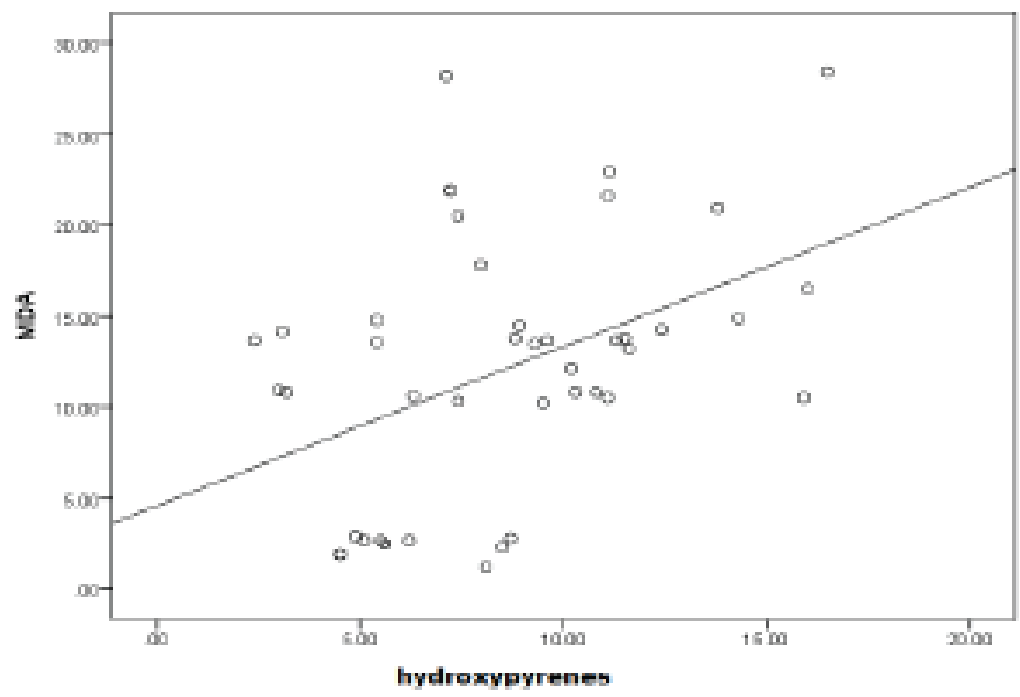

Figure (1): Correlation coefficient between urinary 1-OHpyrene and serum MDA among the exposed workers.

Figure 1 showed a statistically significant positive correlation between urinary $1-\mathrm{OH}$ pyrene and serum MDA among the exposed workers $(\mathrm{P}<0.001)$.

\section{Discussion}

Coal tar workers are exposed to complex, variable mixtures of phenols, polycyclic aromatic hydrocarbons (PAHs) and heterocyclic compounds (Matar and Hatch, 2001). Long-term low-level exposure to PAHs has the potential to interfere with the endocrinal systems. It was reported that PAHs may possess endocrine disruption activity that could affect reproductive health functions of humans (Jeng et al., 2013).
This study was carried out to clarify the association between occupational exposure to PAHs and male reproductive health and investigate the underlying hormonal pathogenesis beside oxidative stress mechanism. To our knowledge, this is one of the scare studies that investigated the potential reproductive risk of PAHs among coal tar workers in Egypt.

The current study showed a statistically significant high level of urinary 1-OH pyrene among the exposed group compared to the control (Table1). 
The level of 1-OH pyrene is affected by the site of exposure rather than the age, smoking and duration of exposure $(\beta=0.52, P<0.05)$, being high among topside workers than other subgroups (Table 4). These results were consistent with Jeng et al., (2013) who stated that topside coke oven workers were at higher exposure to PAHs than sideoven.

The current study showed that there was no statistically significant difference between exposed and control groups as regards cigarette smoking (Table1). Cocco et al., (2007) in their study on the effect of urban traffic, individual habits, and genetic polymorphisms on background urinary 1-hydroxypyrene excretion concluded that the level of urinary 1-OHpyrene was unaffected by age, or smoking status, even passive smoking. However, Chuang and Chang (2007) had linked cigarette smoking to increased 1-OHpyrene levels.

Exposure to PAHs is a contributory factor to the oxidative stress through the formation of reactive oxygen species (ROS) (Prahalad et al., 2001). The generated ROS interact indirectly causing lipid peroxidation and generation of MDA (Voulgaridou et al., 2011).

In the present study, serum MDA was significantly higher among exposed workers especially topside workers (Table1, 4). This may be explained by the higher $1-\mathrm{OH}$ pyrene level in topside workers, indeed, age and $1-\mathrm{OH}$ pyrene level were considered a significant predictor for MDA level $(\beta=1.32$, $\mathrm{p}<0.05, \beta=0.67, \quad \mathrm{p}<0.05$ respectively) ( the results are not tabulated). This is in accordance with Pan et al., (2008) and Suresh et al., (2009) who reported that accumulation of MDA-DNA adducts occurred after chronic exposure to PAHs and urinary 1-OH pyrene level which is a significant predictors for serum MDA. Smoking was not found to be a predictor for the level of MDA in our study (the results are not tabulated). However, Mitev et al., (2010) linked smoking with elevated serum level of MDA.

Many studies have concluded that exposure to PAHs is associated with both semen affection and reproductive hormones disturbance (Jeng and Yu, 2008 and Kim et al., 2013). The results of the current study showed a significant reduction in the seminal fluid volume, sperm concentration and motility (grade B) with increase in pus cells among the exposed group ( Table $3)$.This goes in accordance with Xia et al., (2009) in their study on the relation between urinary metabolites of PAH and human semen quality; they linked the decrease in sperm concentration, morphology, and motility with high level of 1-OH pyrene. This may be due to damage of sperm DNA and apoptosis of mature sperm (Jeng and Yu, 2008).

As about reproductive hormones, the results of the present study revealed 
an increase in FSH, Estradiol (E2) and Estradiol ratio and decrease in testosterone among the exposed group compared to the control but only Estradiol ratio reached the statistical significant level (Table 1). The decrease in the circulating concentrations of testosterone happened secondary to the exposure of the Leydig cells to 1-OH pyrene which compete for androgen receptors and decrease in intratesticular androgen binding proteins which are required for the maintenance of high concentrations of testosterone in the testis (Jeng and Yu, 2008)). As well, Ahmad et al., (2010) added that the oxidative stress secondary to PAHs exposure caused a decline in the serum level of Testosterone $(\mathrm{T})$ and Prolactin. The progressive $\mathrm{T}$ decline is associated with relative and/ or absolute increase in serum estradiol $\left(E_{2}\right)$ with consequent increase in estradiol ratio (Ramesh et al., 2008 and Srilatha and Adaikan, 2011 ).

A significant positive correlation was found between MDA and both 1-OH pyrene and LH hormone, while no significant correlations were detected concerning other hormones and semen parameter (the results are not tabulated). These were in agreement with the study done by Aprioku and Ugwu (2015) who found significant positive correlation between the serum level of MDA and LH hormone.

It is worth noting that on further subdivision of the exposed workers,
Testosterone and Prolactin levels were significantly lower among Top side workers with significant increase in sperm abnormal form than in office side and control group respectively (Table 4). These results agreed with Jeng et al., (2013) who found an association between high degree of PAHs exposure (top side workers) and the increased sperms abnormality per ejaculum. This can be explained by the elevated level of MDA resulting in damage to the plasma membrane of spermatozoa with decrease in motility (Tavilani et al., 2005). Also, Ahmad et al., (2010) mentioned that the oxidative stress occurred secondary to PAHs exposure causing a decline in the serum level of Testosterone and Prolactin and these disturbances were improved after receiving antioxidant medications. However, Han et al., (2010) found no significant changes in Estradiol level and Prolactin hormones after chronic PAHs exposure.

On doing erectile dysfunction score (ED score), there was a significant decrease in the total score among the exposed group (moderate and severe grades). It was shown that Testosterone, Estradiol ratio and aging were a predictor for $\mathrm{ED}(\beta=0.96, \mathrm{P}<0.05, \beta=0.86$, $\mathrm{p}<0.05)$ respectively; smoking, $1-\mathrm{OH}$ pyrene and MDA, were not considered. Similarly, Harlev et al., (2015) and Smith et al.(2016) stated that both Estradiol ratio and Testosterone hormone are strongly correlated with ED and no 
relation was found between ED and 1-OH pyrene. Indeed, the multifactorial causes of ED explain the difficulty of evaluation and treatment (Papagiannopoulos et al., 2015).

However, recent studies have correlated low levels of prolactin in men with sexual disorders and psychological fluctuations(Maria, 2016). Corona et al., 2014 found that the disturbed prolactin level doesn't interfere with the sexual function which is similar to the results obtained from this study (Table2).

\section{Conclusion and recommendations:}

Coal tar workers were exposed to PAH which was detected by high level of $1-\mathrm{OH}$ pyrene as a metabolite with consequent affection of male reproductive health as shown in the results of the current study.

This raises the need for further research work, good ventilation at the workplace and the use of adequate personal protective equipment.

\section{Acknowledgement}

The authors would like to thank all the workers who generously agreed to participate and also the administration of the factory that facilitated the access to the study group.

\section{Financial support}

None

\section{Conflict of interest}

There is no conflict of interest.

\section{References}

1. Ahmad MK, Mahdi AA, Shukla KK, Islam N, Rajender S, et al. (2010): Withania somnifera improves semen quality by regulating reproductive hormone levels and oxidative stress in seminal plasma of infertile males. Fertil Steril ; 94(3): 989-96.

2. Aprioku JS and Ugwu TC (2015): Comparative Evaluation of the Impact of Subacute Exposure of Smokeless Tobacco and Tobacco Smoke on Rat Testis. Inter $\mathbf{J}$ Reprod Medicine; Article ID 676245, 10 pages. doi: 10.1155/2015/676245.

3. Armstrong B, Hutchinson E, Unwin J and FletcherT(2004): Lung cancer risk after exposure to polycyclic aromatic hydrocarbons: A review and meta-analysis. Environ Health Perspectives; 112(9): 970-8.

4. Chuang CY and Chang CC (2007): Urinary 1-hydroxypyrene level relative to vehicle exhaust exposure mediated by metabolic enzyme polymorphisms. J Occup Health; 49(2):140-51.

5. Cocco P, Moore PS, Ennas MG, Tocco MG, Ibba A, et al. (2007): Effect of urban traffic, individual habits, and genetic polymorphisms on background urinary 1-hydroxypyrene excretion. Ann Epidemiol; 17(1):1-8.

6. Corona G, Wu FC, Rastrelli G, Lee DM, Forti G, et al. (2014): Low Prolactin Is Associated with Sexual Dysfunction and Psychological or Metabolic Disturbances in Middle-Aged and Elderly Men: The European Male Aging Study (EMAS). J Sex Medicine; 11(1): 240-53. 
7. Ghanwat GH, Patil AJ, Patil JA, Kshirsagar MS, Sontakke A, et al. (2016): Biochemical effects of lead exposure on oxidative stress and antioxidant status of battery manufacturing workers of Western Maharashtra, India. J Basic and Clinical Physiology and Pharmacology; 27(2): 141-6.

8. Guller U and DeLong ER (2004): Interpreting statistics in medical literature: a vade mecum for surgeons. J Am Coll Surg; 198(3):441-58.

9. Harlev A, Agarwal A, Gunes SO, Shetty A, du Plessis SS (2015): Smoking and Male Infertility: An Evidence-Based Review. World J Men's Health; 33(3):143-60.

10. Han Y, Xia Y, Zhu P, Qiao S, Zhao R, et al. (2010): Reproductive hormones in relation to polycyclic aromatic hydrocarbon (PAH) metabolites among non-occupational exposure of males. Sci Total Environment; 408(4): 768-73.

11. Hsu PC, Chen YY, Pan CH, Wu KY, Pan $\mathrm{MH}$, et al (2006): Sperm DNA damage correlates with polycyclic aromatic hydrocarbons biomarker in coke-oven workers. Inter Arch Occup and Environ Health; 79(5): 349-56.

12. Hu YA, Lu JC, Shao Y, Huang Y F and Lu NQ (2013): Comparison of the semen analysis results obtained from two branded computer-aided sperm analysis systems. Andrologia; 45:315-8.

13. Jeng HA and Yu L (2008): Alteration of sperm quality and hormone levels by polycyclic aromatic hydrocarbons on airborne particulate particles. J Environ Sci and Heal A, Toxic/hazardous Substances \& Environmental Engineering 43(January 2015): 675-81.

14. Jeng HA, Pan CH, Lin WY, Wu MT, Taylor S, et al. (2013): Biomonitoring of polycyclic aromatic hydrocarbons from coke oven emissions and reproductive toxicity in nonsmoking workers. J Hazard Mater; 15:244-5, 436-43.

15. Kang HG, Jeong $\mathrm{SH}$, Cho $\mathrm{MH}$ and Cho JH (2007): Changes of biomarkers with oral exposure to benzo (a) pyrene, phenanthrene and pyrene in rats. J Vet Sci; 8 (4):361-8.

16. Kim KH, Jahan SA, Kabir E and Brown RJ (2013): A review of airborne polycyclic aromatic hydrocarbons (PAHs) and their human health effects. Environ Intern; 60: 71-80.

17. Lerda D (2010): Polycyclic Aromatic Hydrocarbons (PAHs) Factsheet. JRC Technical Notes, 3, 1-25pitch. Solid Fuel Chemistry; 49(4), 213-25.

18. Maria M (2016): The Role of Prolactin in Men. Endocrinology and Metabolic Syndromes; 5: 222.

19. Matar S and Hatch L (2001): Chemistry of petrochemical processes. 2nd Edition ISBN: 9780884153153, 9780080501086

20. Meeker JD, Ryan L, Barr DB and Hauser R (2006): Exposure to non persistent insecticides and male reproductive hormones. Epidemiology (Cambridge, Mass), 17(1): 61-68.

21. Mitev D, Gradeva H, Stoyanova Z, Petrova N, Karova N et al. (2010): Evaluation of thiol compounds and lipid peroxidative products in plasma of patients with COPD. Trakia J Sci; 8 (2): 306-14

22. Papagiannopoulos $\mathrm{D}$, Khare $\mathrm{N}$ and Nehra A (2015): Evaluation of young men with organic erectile dysfunction. Asian J Andrology;17(1): 116.

23. Pan $\mathrm{CH}$, Chan $\mathrm{CC}$, Huangand $\mathrm{YL}$ and $\mathrm{Wu}$ KY (2008): Urinary 1-hydroxypyrene and malondialdehyde in male workers in Chinese restaurants. Occup and Environ Medicine; 65(11): 732-35. 
24. Perera FP, Tang D, Rauh V, Lester K, Tsai WY, et al, (2005): Relationships among polycyclic aromatic hydrocarbon-DNA adducts, proximity to the World Trade Center, and effects on fetal growth. Environ Health Perspect; 113(8):1062-7.

25. Prahalad AK, Inmon JD, Madden MC, Ghio AJ and Gallagher JE (2001): Air Pollution Particles Mediated Oxidative DNA Base Damage in a Cell Free System and in Human Airway Epithelial Cells in Relation to Particulate Metal Content and Bioreactivity. Chem Res in Toxicology, 14(7): 879-87.

26. Ramesh A, Inyang F, Lunstra DD, Niaz MS, Kopsombut P, et al. (2008): Alteration of fertility endpoints in adult male F-344 rats by subchronic exposure to inhaled benzo(a)pyrene. Exp and Toxi Pathology, 60(4-5): 269-80.

27. Ravindra K, Sokhi R and Grieken RV (2008): Atmospheric polycyclic aromatic hydrocarbons: source attribution, emission factors and regulation. Atmos Environ, 42 913); 2895-2921.

28. Rosen RC (2001): Psychogenic erectile dysfunction: Classification and management. Urologic Clinics of North America; 28(2), 269-78.

29. Smith R, Lipshultz L and Kovac J (2016): Estradiol exerts alterations in sexual function and fertility in human males. Asian $\mathbf{J}$ Andrology; 18(3):441.

30. Sofikitis N, Giotitsas N, Tsounapi P, Baltogiannis D, Giannakis D, et al. (2008): Hormonal regulation of spermatogenesis and spermiogenesis. J Steroid Biochemistry and Molecular Biology; 109(3-5), 323-30.

31. Sokol RZ (2009): Endocrinology of Male Infertility: Evaluation and Treatment. [Article]. Seminars in Reproductive Medicine
Male Infertility in the Era of ART: Why Treat; 27: 149-58.

32. Srilatha B and Adaikan PG (2011): Endocrine milieu and erectile dysfunction: Is oestradiol-testosterone imbalance, a risk factor in the elderly? Asian J Andrology; 13(4):569-73. DOI: 10.1038/ aja.2010.129.

33. Straif K, Baan R, Grosse Y, Secretan B, El Ghissassi F, et al. (2005): Carcinogenicity of polycyclic aromatic hydrocarbons. The Lancet Oncology; 6, 931-32.

34. Suresh R, Shally A, Mahdi AA, Patel DK, Singh VK, et al. (2009): Assessment of association of exposure to polycyclic aromatic hydrocarbons with bronchial asthma and oxidative stress in children: A case control study. Indian J Occup Environ Med; 13(1):33-7.

35. Tavilani H, Doosti M and Saeidi H (2005): Malondialdehyde levels in sperm and seminal plasma of asthenozoospermic and its relationship with semen parameters. Clinica Chimica Acta; 356(1-2): 199-203.

36. Ulhôa MA, Marqueze EC, Burgos LGA, Moreno CRC and Moreno CRC (2015): Shift work and endocrine disorders. Inter J Endocrinology; 82 (6):249.

37. Voulgaridou GP, Anestopoulos I, Franco R, Panayiotidis MI and Pappa A (2011): DNA damage induced by endogenous aldehydes: current state of knowledge. Mut Res; 711(1-2): 13-27.

38. XiaY, Han Y, Zhu P, Wang S, Gu A, et al. (2009): Relation between Urinary Metabolites of Polycyclic Aromatic Hydrocarbons and Human Semen Quality. Environ Sci Tech; 43(12): 4567-73. 